Abstract PTU-24 Table 1 Outcomes of treatment with Hemospray monotherapy

\begin{tabular}{|c|c|c|c|c|c|c|c|}
\hline & $\begin{array}{l}\text { Peptic ulcer } \\
(\mathrm{N}=62)\end{array}$ & Malignancy $(n=72)$ & $\begin{array}{l}\text { Post endoscopic therapy } \\
(\mathrm{N}=23)\end{array}$ & Lower GI bleeds $(\mathrm{N}=22)$ & $\begin{array}{l}\text { Angiodysplasia } \\
(\mathrm{N}=5)\end{array}$ & $\begin{array}{l}\text { Inflammation } \\
(\mathrm{N}=22)\end{array}$ & Variceal $(\mathrm{N}=7)$ \\
\hline Haemostasis & $56 / 62(90 \%)$ & $72 / 72(100 \%)$ & $23 / 23(100 \%)$ & $21 / 22(96 \%)$ & $\begin{array}{l}5 / 5 \\
(100 \%)\end{array}$ & $\begin{array}{l}21 / 22 \\
(96 \%)\end{array}$ & $4 / 7(57 \%)$ \\
\hline Rockall & $\begin{array}{l}7 \\
(\mathrm{IQR}, 7-8)\end{array}$ & $\begin{array}{l}8 \\
(\mathrm{IQR}, 7-9)\end{array}$ & $\begin{array}{l}6 \\
(\mathrm{IQR}, 5-6)\end{array}$ & $\mathrm{n} / \mathrm{a}$ & $\begin{array}{l}7 \\
(\mathrm{IQR}, 6-7)\end{array}$ & $\begin{array}{l}7 \\
(\mathrm{IQR}, 6-8)\end{array}$ & $\begin{array}{l}8 \\
(I Q R, 7-8)\end{array}$ \\
\hline Re-bleed & $7 / 44(16 \%)$ & $\begin{array}{l}11 / 63 \\
(18 \%)\end{array}$ & $1 / 20(5 \%)$ & $5 / 19(26 \%)$ & $\begin{array}{l}1 / 5 \\
(20 \%)\end{array}$ & $\begin{array}{l}4 / 19 \\
(21 \%)\end{array}$ & $1 / 3(33 \%)$ \\
\hline 7-day mortality & $6 / 50(12 \%)$ & $\begin{array}{l}5 / 63 \\
(8 \%)\end{array}$ & $1 / 20(5 \%)$ & $2 / 20(10 \%)$ & 0 & $\begin{array}{l}5 / 20 \\
(25 \%)\end{array}$ & $3 / 6(50 \%)$ \\
\hline 30-day mortality & $15 / 50(30 \%)$ & $17 / 63(27 \%)$ & $1 / 20(5 \%)$ & $4 / 20(20 \%)$ & 0 & $\begin{array}{l}10 / 20 \\
(50 \%)\end{array}$ & $3 / 6(50 \%)$ \\
\hline
\end{tabular}

Results 62 patients with peptic ulcer bleeds were treated. There was an immediate haemostasis of 90\% (56/62), re-bleed rate of $16 \%$ (7/44) (Table 1). 69\% were Forrest $1 \mathrm{a} / 1 \mathrm{~b}$ ulcers.

72 patients with malignancy related bleeds. There was a haemostasis rate of $100 \%$ and a re-bleed rate of $18 \%(11 / 63)$. There was a haemostasis rate of $100 \%$ with post endoscopic therapy bleeds. $48 \%$ were post endoscopic mucosal resection.

22 patients with lower GI bleeds were treated. 36\% secondary to colonic tumours. There was a haemostasis rate of $96 \%(21 / 22)$ and re-bleed of 26\% (5/19). A 100\% haemostasis was achieved in 5 patients treated for gastric angiodysplasia with one re-bleed.

Conclusions Results show high haemostasis and comparable rebleed rates with Hemospray monotherapy treatment. It may play a potential role in actively bleeding peptic ulcers in difficult anatomical positions to help bridge towards definitive therapy. These data may represent the evolution of new treatment paradigms as experience with haemostatic powders increases.

\section{PTU-25 DELIBERATE FOREIGN BODY INGESTION DURING COVID-19}

Andrew Phillips*, Kate Axe. Nevill Hall Hospital, Abergavenny, UK

\subsection{6/gutjnl-2021-BSG.98}

Introduction For patients with Foreign body ingestion (FBI) $10-20 \%$ of FBI require endoscopic investigation ${ }^{1}$. Common non-food objects swallowed include paperclips, coins, pens, batteries \& razors.

$92 \%$ of non-food ingestion is deliberate (DFBI), considered a type of deliberate self-harm (DSH) ${ }^{2}$. DFBI is often recurrent, leading to high healthcare costs.

Our team noted an increase in OGD for DFBI during the COVID-19 pandemic, we compared our experiences in 2020 with those of $2018 \& 2019$ and reviewed their management.

Method Retrospective case notes study for OGD referrals for 'foreign body'. Data obtained from EMS endoscopy and Clinical Workstation (CWS). PEG change/removal and OGD post object passage were excluded.

Results Between 2018 \& 2020, 23 procedures were performed for DFBI; 13/23 (57\%) needed General Anaesthetic (GA). 7/ 23 of procedures (30\%) used an overtube, 6 (86\%) under GA.

\begin{tabular}{llll}
\multicolumn{3}{l}{ Abstract PTU-25 } & Table 1 \\
\hline & 2018 & 2019 & 2020 \\
\hline $\begin{array}{l}\text { Total FBI } \\
\text { Referral }\end{array}$ & 10 & 20 & 31 \\
$\begin{array}{l}\text { Total DFBI } \\
\begin{array}{l}\text { Number of } \\
\text { patients } \\
\text { Objects }\end{array}\end{array}$ & $2(20 \%)$ & $4(20 \%)$ & $17(55 \%)$ \\
& 2 & 9 \\
\hline
\end{tabular}

No object was found in 2 OGD. Surgical management was required in 2 OGD. In 29/61 procedures one or more objects was retrieved.

Discussion 2020 demonstrated a marked increase in OGD for FBI, of which 55\% were DFBI compared with $20 \%$ in preceding years. All patients were $\leq 40$ years of age. Commonest objects were long e.g. pens or high risk e.g. batteries/razors. However, a wider variety of objects were swallowed during the pandemic.

Our outcomes reflect those in published data ${ }^{1}$, with most procedures successful when objects were known to be in the stomach.

DFBI is often spontaneous and stress related, rather than a suicide attempt, on a background of complex personality disorder. It is thought DFBI gives a psychological 'gain' in forcing care, with multiple healthcare contacts resulting from the act $^{2}$.

Care plans are common in other forms of DSH but lacking in DFBI. These may benefit repeat attenders, ensuring endoscopy only performed when strictly necessary and minimising the psychological gain from the act.

Mental health issues have increased during the pandemic, this has impacted on already stretched endoscopy services with increase in DFBI, possibly due to decreased access to psychiatric services. This act is resource intensive and difficult to manage, a care plan should be considered after admission with DFBI.

4. Birk $\mathrm{M}$ et al. Removal of foreign bodies in the upper gastrointestinal tract in adults: ESGE Clinical Guideline. Endoscopy. 2016:48;1-8

1. Poynter B et al. Hard to Swallow: A systematic review of deliberate foreign body ingestion. Gen Hosp Psych. 2011:33(5);518-524 
Palese C, Al-kawas F. Repeat intentional foreign body ingestion: the importance of a multidisciplinary approach. Gast \& Hep. 2012: 8(7); 485-489

\section{PTU-26 HORIBE VS CONVENTIONAL RISK SCORING: PREDICTING NEED FOR ENDOSCOPIC INTERVENTION IN ACUTE UPPER GASTROINTESTINAL BLEED}

${ }^{1}$ Eilidh Mcgowan*, ${ }^{1}$ Thomas Riley, ${ }^{2}$ Keith Siau, ${ }^{1}$ Martin Crossdale, ${ }^{1}$ Matthew Saxton, 'Wisam Jafar. 'Department of Gastroenterology, Stockport Foundation Trust., Stockport, UK; ${ }^{2}$ Department of Gastroenterology, Dudley Group Hospitals NHS Foundation Trust., Dudley, UK

\subsection{6/gutjnl-2021-BSG.99}

Introduction The recently developed Horibe score was shown to be superior to the Glagow Blatchford Score (GBS) in predicting endoscopic therapy in acute upper gastrointestinal bleeding (AUGIB). However, this has not been validated in the UK. We aimed to compare the Horibe score ${ }^{[1]}$ with other AUGIB risk assessment tools to identify the optimal risk stratification tool for predicting endoscopic therapy in AUGIB.

Methods All patients presenting to Stockport Foundation Trust over a 7 month period (1st June 2019 to 1st January 2020) who underwent gastroscopy for AUGIB were included. Glasgow Blatchford score was calculated prospectively on admission with the Horibe(1), Shock index, Pre-endoscopy Rockall and AIM65 being calulcated retrospectively. Receiver operating characteristics (ROC) curves for each risk assessment score were generated to determine their ability to predict endoscopic therapy, with pairwise comparisons made between ROC curves to determine statistical significance.

Results Of the 150 patients included for analysis, endoscopic therapy was delivered in 28 patients (18.7\%). This outcome was best predicted by the GBS (AUROC 0.759; 95\% confidence interval 0.664-0.855) [Figure 1]. GBS performed significantly better than the Horibe score (AUROC 0.583, $\mathrm{P}=0.009$ ), AIMS65 (AUROC 0.538, $\mathrm{P}=0.001$ ), pre-endoscopic Rockall (AUROC 0.635, P=0.027) and shock index (AUROC

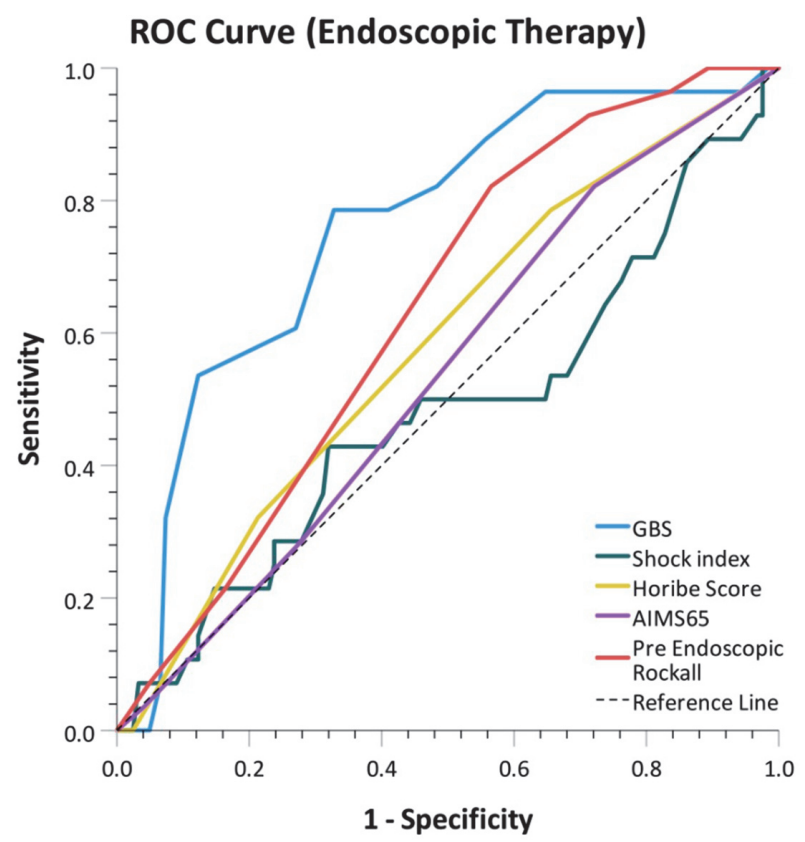

Abstract PTU-26 Figure 1 ROC curve (Endoscopic Therapy)
0.481, $\mathrm{P}<0.001)$. On sensitivity analysis, the GBS remained superior in patients with and without cirrhosis. A GBS theshold of $\geq 10$ provided the optimal sensitivity (78.6\%) and specificity $(67.2 \%)$ for predicting endotherapy.

Conclusion The GBS appears superior to the Horibe score for predicting endoscopic therapy in AUGIB. In line with the BSG AUGIB care bundle ${ }^{[2]}$, our evidence suggests that GBS should be used as the risk stratification tool of choice in AUGIB.

\section{REFERENCES}

1. Horibe M, Iwasaki E, Bazerbachi F, Kaneko T, Matsuzaki J, Minami K, Masaoka T, Hosoe N, Ogura Y, Namiki S, Hosoda Y, Ogata H, Chan AT, Kanai T. Horibe GI bleeding prediction score: a simple score for triage decision-making in patients with suspected upper GI bleeding. Gastrointest Endosc. 2020 Sep;92(3):578-588. e4. doi: 10.1016/i.gie.2020.03.3846. Epub 2020 Mar 30. PMID: 32240682.

2. Siau K, Hearnshaw S, Stanley AJ, et al. Frontline Gastroenterology 2020;0:1-13. doi:10.1136/flgastro-2019-101395

\section{PTU-27 IMPACT OF COVID-19 ON UGI TRACT STENTING AND DILATATION SERVICES- PRIORITISE, KEEP SCOPING AND TRAINING}

Chia Chuin Yau*, Shiran Esmaily, Deepak Dwarakanath, John Hancock, Mitra Vikramjit. University Hospital of North Tees, Stockton on Tees, UK

\subsection{6/qutinl-2021-BSG.100}

The COVID-19 pandemic profoundly affected endoscopy services including therapeutic gastroscopy across the UK. The BSG issued guidance for managing endoscopy services safely throughout this period. At the beginning of the pandemic in March 2020, a symptom-based questionnaire was used to screen patients for COVID-19 prior to their endoscopic procedures in our hospital (COVID-19 swabs were only carried out if patients presented with COVID-19 symptoms). From 18 May 2020 onwards, in addition to the above approach, all patients attending endoscopic procedures underwent a SARSCoV-2 nasopharyngeal swab 1-3 days prior to the procedure. We describe our experience of UGI stenting and dilatation during the initial wave of COVID-19 pandemic in the UK.

Aim of the study To assess the impact of COVID-19 pandemic on technical and clinical success of luminal dilatation and stenting in the UGI tract and ascertain the risk of procedure related complications.

Methods A retrospective audit of a prospectively maintained endoscopy database was carried out between 18th March and 31st July. All patients were followed for 30 days. Full PPE were used.

Results 42 procedures [31 were oesophageal dilatation (21 peptic stricture, 9 radiotherapy stricture, 1 achalasia), 8 oesophageal stent insertion (6 for primary oesophageal cancer, 1 metastatic cancer and 1 secondary to external compression from lung cancer) and 3 pyloric dilatation all benign] were carried out- mean age 65 years, $64.3 \%$ males, $81 \%$ of procedures were carried out as outpatients. All procedures were performed under fluoroscopy. 41/42 (97.6\%) patients had a confirmed histology prior to their procedure - one patient who underwent oesophageal dilatation had a peptic stricture on endoscopy (no biopsy or cross-sectional imaging). 39/42 (92.9\%) patients had undergone a CT scan and/or barium swallow prior to their first procedure. All procedures were technically and clinically successful (100\%). There were no procedure related complications or mortality. There were no COVID positive swabs in the 30 - day post procedure period during the entire study period. Trainees were present in $21 / 42$ 